\title{
Faropenem Medoxomil
}

National Cancer Institute

\section{Source}

National Cancer Institute. Faropenem Medoxomil. NCI Thesaurus. Code C65621.

A daloxate ester prodrug form of faropenem, a penem with a tetrahydrofuran

substituent at position C2, with broad-spectrum antibacterial activity ag ainst many grampositive and gram-negative aerobes and anaerobes. Faropenem medoxomil is hydrolyzed in vivo to release the active free acid. Compared with imipenem, faropenem has improved chemical stability and reduced central nervous system effects. In addition, faropenem is resistant to hydrolysis by many beta-lactamases. 